\title{
Utilização de um antígeno comercial para o teste ELISA indireto na detecção de anticorpos contra a brucelose ovina
}

\author{
Use of a commercial antigen for detection of ovine \\ brucellosis antibodies through indirect ELISA
}

luri Coelho Greve $e^{[a]}$, Maurício Costa Alves Silva ${ }^{[b]}$, Soraya Trindade ${ }^{[c]}$, Diógenes Silva[ ${ }^{[d]}$, Maria Teresa Mascarenhas[e], Robson Cerqueira Bahia ${ }^{[f]}$

[a] Mestre em Ciência dos Animais nos Trópicos pela Universidade Federal da Bahia, Escola de Medicina Veterinária, Departamento de Medicina Veterinária Preventiva (UFBA), Salvador, BA - Brasil, e-mail: iurigreve@yahoo.com.br

[b] Doutor em Microbiologia pela Universidade Federal da Bahia, Escola de Medicina Veterinária, Departamento de Medicina Veterinária Preventiva (UFBA), Salvador, BA - Brasil, e-mail: e-mail: mcasilva@hotmail.com

[c] Doutora em Imunologia pela Universidade Federal da Bahia, Escola de Medicina Veterinária, Departamento de Medicina Veterinária Preventiva (UFBA), Salvador, BA - Brasil, e-mail: soraya@uefs.br

[d] Técnico em Análises Laboratoriais pela União Metropolitana de Educação e Cultura-UNIME, Lauro de Freitas, BA - Brasil.

[e] Mestre em Ciência dos Animais nos Trópicos pela União Metropolitana de Educação e Cultura-UNIME, Lauro de Freitas, BA Brasil, e-mail: mtmascarenhas@terra.com.br

[f] Doutor em Microbiologia pela Universidade Federal do Recôncavo Baiano (UFRB), Cruz das Almas, BA - Brasil, e-mail:robsonba@gmail.com

\section{Resumo}

O estudo avaliou o antígeno comercial Reo 198, composto de fragmentos de lipopolissacarídeos da Brucella ovis com vistas ao diagnóstico de anticorpos contra a B. ovis utilizando o teste ELISA indireto. 0 antígeno foi diluído a 1:200 e submetido às amostras oriundas de animais com histórico e sem manifestação clínica da enfermidade. Noventa amostras foram empregadas, sendo 45 provenientes de animais com histórico de aborto e epididimite e 45 de animais sem histórico da doença. Após padronização e determinação do ponto de corte, 448 amostras de soro ovino com histórico clínico de outras enfermidades foram submetidas ao teste visando detectar possível reação ao teste. As mesmas 90 amostras foram submetidas à Imunodifusão em gel de agarose (IDGA). 0 estudo da sensibilidade e especificidade demonstrou um bom desempenho do teste com percentuais de $100 \%$ e 95,6\%, respectivamente. Das 448 amostras submetidas ao ELISA padronizado, 11 foram reagentes ao teste, mas não reagentes ao IDGA.

Palavras-chave: Brucelose ovina. Sorodiagnóstico. ELISA indireto. IDGA.

\section{Abstract}

The present study evaluated the use of a commercial antigen, called Reo 198, composed by lipopolysaccharide fragments of Brucella ovis for the diagnosis of brucellosis through indirect ELISA. The antigen was used (at a dilution ratio of 1:200) to analyze samples from animals with and without clinical history of the disease. Ninety 
samples were tested: 45 from animals with clinical history of abortion and epididymitis and 45 from healthy subjects. These 90 samples were also submitted to the agar-gel immunodiffusion test (AGID) for comparison between methods. After standardization and determination of the cutoff point, 448 ovine serum samples from animals involved with different diseases were submitted to the ELISA test in order to detect possible interferences. Eleven of the 448 samples showed a false positive result for the ELISA method, but did not react to the AGID test. Sensitivity and specificity tests demonstrated that the ELISA method is 100\% sensitive and 95.6\% specific.

Keywords: Fish Silage. Productive Performance. Retention Efficiency.

\section{Introdução}

A Brucella ovis é um dos principais agentes etiológicos da epididimite em ovinos, associado à redução da fertilidade em muitos animais dessa espécie, causando aborto e esterilidade em fêmeas. 0 diagnóstico tem sido executado mediante palpação da bolsa escrotal, isolamento e identificação da bactéria por meio da cultura do sêmen ou testes sorológicos (ARSENAULT et al., 2004). Em casos agudos, os testículos estão aumentados de tamanho, há edema inflamatório e presença de exsudado fibrinoso na região da túnica vaginal, hiperemia testicular e edema do epidídimo (ROBLES, 1998). Na fase crônica, são observadas regiões hipertrofiadas no testículo e endurecidas à palpação, deformações na cauda do epidídimo, espessamento da bolsa escrotal, fibrose, restringindo a mobilidade testicular, além de aderências fibrosas obstruindo a cavidade que separa as túnicas (RIDLER, 2002).

0 manejo e a frequência de higienização das instalações são fatores extremamente importantes para o controle da brucelose. Tais variáveis caracterizam a ovinocultura de subsistência e o sistema extensivo, no qual os animais permanecem soltos em grandes áreas e o criador não exerce nenhum controle sanitário ou reprodutivo, perfil predominante nas regiões Norte e Nordeste do Brasil (SOUZA et al., 2007). Na Bahia, Silva et al. (2009) relatam que é necessária a adoção de medidas sanitárias de controle e prevenção a fim de evitar a propagação da doença. Além desse aspecto, os autores ressaltam a importância da pesquisa direcionada aos produtores de animais de alto padrão genético e econômico, acarretando ainda mais prejuízos para a ovinocultura no estado. O Estado da Bahia concentra 2,8 milhões de ovinos, o maior plantel dessa espécie. Largamente explorados de forma extensiva, os animais têm aumentado seu contingente populacional em função da rusticidade e da adaptação ao meio ambiente, onde predomina a vegetação da caatinga (LEITE, 2000). A prova laboratorial de eleição utilizada para o diagnóstico da Brucella ovis em países como o Brasil, Chile, Argentina e Uruguai é o teste de imunodifusão em gel de ágar, apresentando sensibilidade em torno de $96,4 \%$ e $100 \%$ de especificidade, com baixo custo e fácil interpretação (MYERS; SINIUK, 1970). Apesar de a prova ser considerada de menor custo e de fácil execução, os resultados obtidos são inconclusivos, pois outros microrganismos como Actinobacillus seminis, Histophilus ovis e Corynebacterium spp também podem produzir epididimite palpável e nem todos os carneiros infectados com Brucella ovis desenvolvem epididimite (COLETO et al., 2003). Desse modo, Pinheiro Junior et al. (2009) recomendam que, para o diagnóstico da Brucella ovis em machos, seja realizado o teste sorológico, associado ao exame clínico rigoroso, ressaltando-se que seria mais indicado o exame microbiológico para o isolamento do agente.

0 presente estudo teve como objetivo avaliar o antígeno comercial Reo 198 em um teste ELISA indireto visando à detecção de anticorpos contra a Brucella ovis.

\section{Materiais e métodos}

\section{Amostras}

\section{Desempenho do antígeno e padronização} do teste ELISA indireto

Foram utilizadas 90 amostras de soro ovino, fornecidas gentilmente por um laboratório da região de Andorinha (BA), compostas por animais de ambos os sexos e idade entre 1 e 8 anos, sendo que 45 apresentavam histórico de epididimite nos machos 
e relato de aborto nas fêmeas, e 45 amostras de animais sem histórico da doença. Todas as amostras foram submetidas ao teste de IDGA recomendado pelo MAPA, utilizando-se o antígeno Reo 198.

Com a finalidade de conferir o desempenho demonstrado pelo teste ELISA padronizado, 448 amostras de soro ovino, fornecidas pelo Laboratório de Virologia da Escola de Medicina Veterinária da Universidade Federal da Bahia, foram submetidas ao teste. As amostras foram colhidas da região do semiárido baiano, nos municípios de Juazeiro, Sobradinho, Casa Nova, Sento Sé, Pilão Arcado, Remanso e Campo Alegre de Lourdes.

Imunodifusão em gel de agarose (IDGA)

0 antígeno utilizado foi o do laboratório TECPAR, partida 003/9, fabricação em novembro de 2009 e vencimento em novembro de 2010, licenciado pelo Ministério da Agricultura. Foram distribuídos $4 \mathrm{~mL}$ de gel de ágar em placas na concentração de 1\% até a solidificação do gel e cortados os poços com a roseta; em seguida, foram adicionados $30 \mu \mathrm{L}$ por poço central do antígeno, soro controle positivo e soro teste, com a leitura 48 horas após a execução, sendo observada a linha de precipitação dos soros reagentes, com a ajuda de uma luz indireta em uma caixa de fundo escuro.

\section{Diluição do antígeno}

0 antígeno do extrato de lipopolissacarídeo de Brucella ovis Reo 198 foi diluído em um tampão carbonato-bicarbonato $0,05 \mathrm{M}, \mathrm{pH} 9,6$, nas proporções $1: 25,1: 50,1: 100,1: 200$. Após a diluição foram submetidos à placa de ELISA (COSTAR 3590) para sensibilização e incubada a $4{ }^{\circ} \mathrm{C}$ por 12 horas. Após a sensibilização, foi realizado o protocolo do teste ELISA indireto, utilizando-se amostras de soro de animais comprovadamente positivos e animais comprovadamente negativos, na diluição 1:200.

\section{Ensaio imunoenzimático indireto (ELISA i)}

As placas de poliestireno de fundo chato (marca COSTAR 3590) foram sensibilizadas com $100 \mathrm{~mL}$ do antígeno, diluído a 1:200 (padronização descrita na diluição do Ag), em tampão carbonato-bicarbonato a 0,05M, pH 9,6, incubadas a $4{ }^{\circ} \mathrm{C}$ por 12 horas. Após duas lavagens com PBS contendo 0,1\% de tween-20 (PBS-T20), as placas foram bloqueadas com $200 \mu \mathrm{L} /$ poço de PBS-T20 contendo 5\% de leite desnatado, durante duas horas. A seguir, foram incubadas com $100 \mu \mathrm{L} /$ poço dos soros testes diluídos a 1:100 em PBS-T20 contendo 1\% de leite em pó desnatado durante 1 hora. Após cinco lavagens em PBS-T20, adiciona-se à placa $100 \mu \mathrm{L}$ de imunoglobulinas de coelho anti-imunoglobulina de ovino, conjugada à peroxidase $\left(\mathrm{DAKO}^{\circledR}\right)$, diluída a 1:10.000 em PBS-T20. As placas foram incubadas a $37{ }^{\circ} \mathrm{C}$ por 45 minutos e, em seguida, foram lavadas novamente cinco vezes em PBS-T20 e incubadas com $50 \mu \mathrm{L} /$ poço da solução reveladora (12,5 ml de tampão cítrico-fosfato $\mathrm{pH}$ 5,1 $+4 \mathrm{mg}$ ortofenilenodiamina $+4 \mu \mathrm{L} \mathrm{de} \mathrm{H}_{2} \mathrm{O}_{2}$ ). Deixouse em temperatura ambiente por 15 minutos e a reação foi freada com $25 \mu \mathrm{l}$ de $\mathrm{H}_{2} \mathrm{SO}_{4} 4 \mathrm{~N}$ em cada poço. A leitura foi feita em leitor de ELISA, usando-se filtro de $490 \mathrm{~nm}$ de comprimento de luz.

As 90 amostras submetidas ao teste ELISA indireto serviram para demonstrar que o antígeno comercial é capaz de distinguir animais positivos e negativos associados ao histórico clínico, ressaltando que para o diagnóstico confirmatório é necessário realizar o isolamento e a identificação das amostras submetidas ao ELISA indireto. As 448 amostras que foram submetidas, posteriormente, à padronização do ELISA indireto serviram para avaliar o desempenho do teste.

\section{Determinação do ponto de corte}

O ponto de corte foi estabelecido por meio da curva Receiver Operator Characteristic (ROC) (ou curva operacional relativa). Essa análise tem como base uma curva na qual são colocados os valores de corte que têm no eixo das ordenadas a sensibilidade e no eixo das abscissas a taxa de falso positivo (1 - especificidade). 0 ponto de corte considerado ideal é aquele que permite uma maior especificidade sem perda da sensibilidade. De acordo com Greiner et al. (1995), essa análise deve ser utilizada para testes ELISA.

\section{Resultados}

Das 90 amostras submetidas ao IDGA, 36 apresentaram reação com formação de linha de preci- 
pitação. Das 54 amostras de animais não reagentes ao teste, nove que apresentaram clínica compatível com a enfermidade foram negativas. 0 mesmo total foi submetido ao ELISA indireto; nele, 45 das 90 amostras apresentaram reação ao teste e com histórico clínico da doença e 45 não apresentaram reação e sem histórico clínico da enfermidade, demonstrando a capacidade do ELISA em discriminar animais reagentes e não reagentes. As amostras de animais sem histórico clínico da doença com variação da densidade óptica foi de 0,114 a 0,561. As amostras dos animais que tinham histórico de epididimite e aborto, e que foram testadas em ambos os testes no ELISA indireto tiveram uma densidade óptica (D.O.) média entre 0,468 e 2,576 (Figura 1). As amostras não reagentes ao teste de imunodifusão tiveram uma D.O. média de 0,1787 . Das nove amostras que tinham histórico da doença e que não reagiram ao IDGA, todas apresentaram reação no ELISA indireto. Duas das 45 amostras que foram submetidas ao teste ELISA indireto que não tinham histórico da doença apresentaram reação.

0 ponto de corte foi definido por meio da curva ROC, que avalia a sensibilidade em função da especificidade. A área delimitada pela curva do teste ELISA indireto com antígeno comercial (Reo 198) apresentou bom desempenho com relação à especificidade e sensibilidade (Figura 2). A partir do desempenho de sensibilidade e especificidade, verificou-se o melhor valor de ponto de corte (Tabela 1).

Na Tabela 1 demonstram-se os valores de porcentagem do desempenho de sensibilidade, especificidade e ponto de corte.

Das 448 amostras submetidas ao ELISA indireto padronizado, 11 foram reagentes ao teste, mas não reagentes ao IDGA, considerando-se o ponto de corte de 0,408. A densidade óptica variou entre 0,186 a 0,234 nas amostras que se apresentaram abaixo do ponto de corte. Já as amostras com valores acima

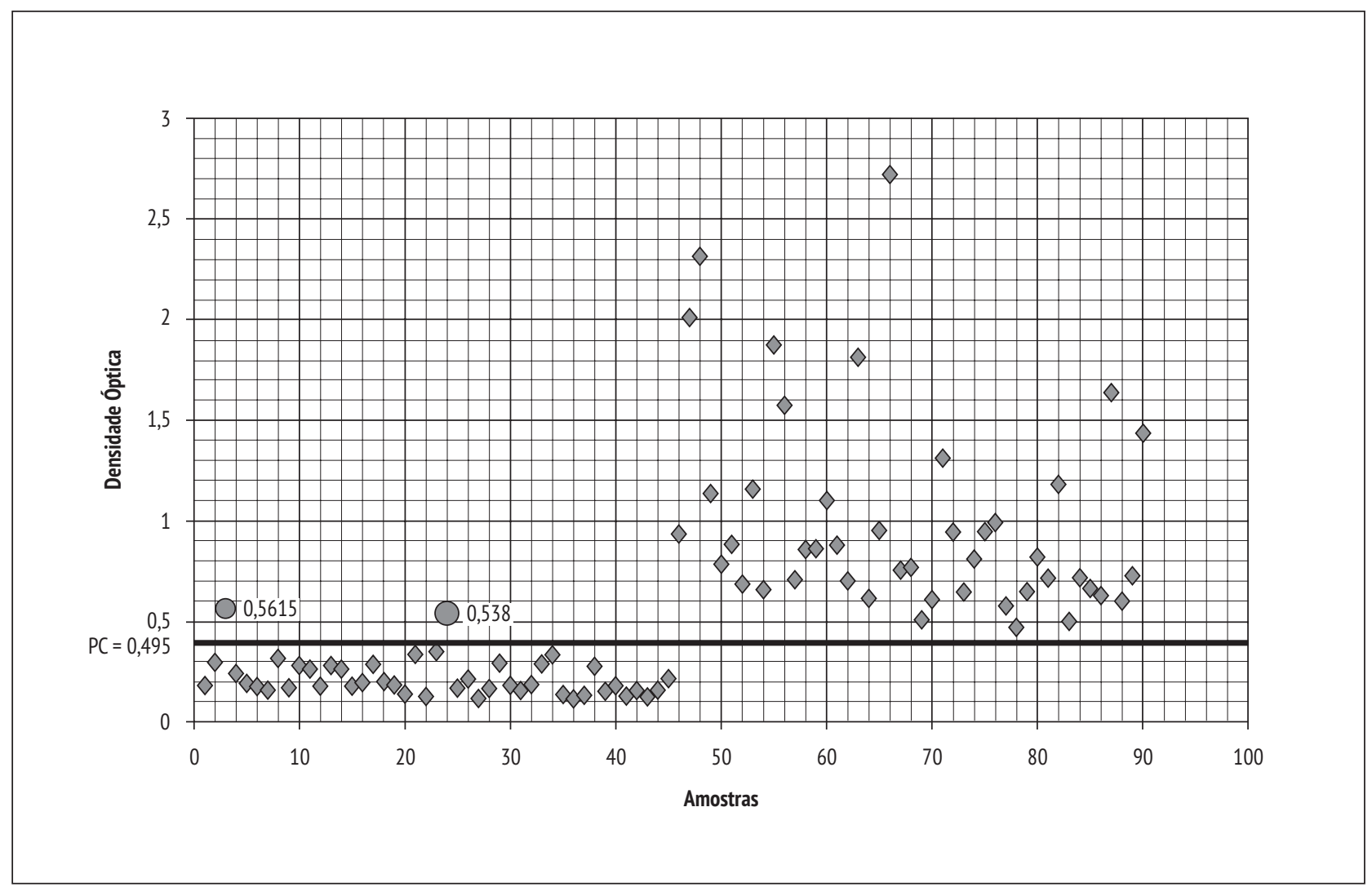

Figura 1 - Amostras de soro ovino sem histórico clínico (abaixo do ponto de corte) e com histórico clínico (acima do ponto de corte) submetidas ao teste ELISA indireto para a detecção de anticorpos contra a brucelose ovina $(\mathrm{n}=90)$

Fonte: Dados da pesquisa. 


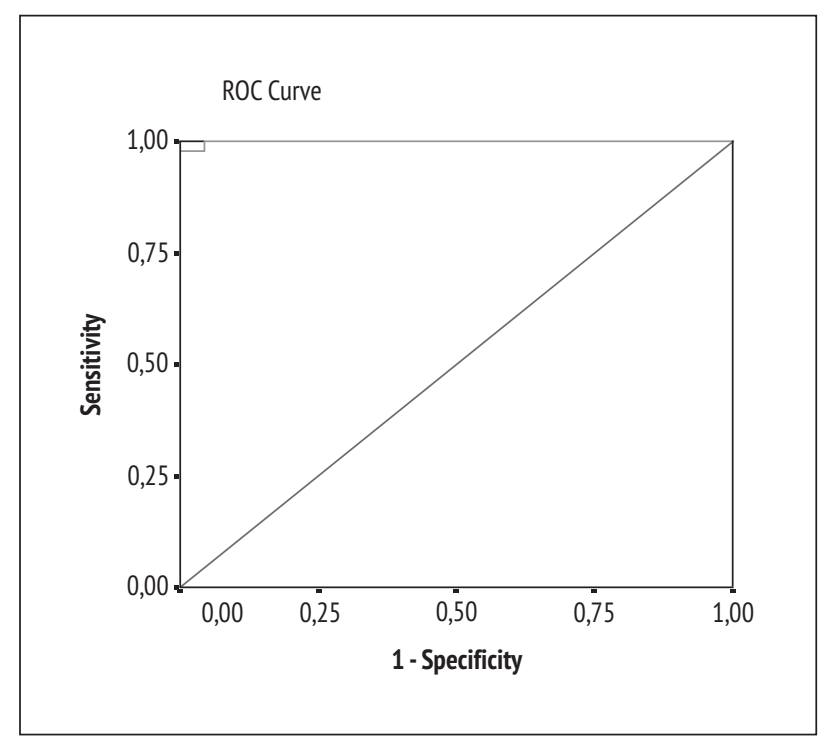

Figura 2 - Curva ROC para avaliação da sensibilidade X especificidade de ELISA indireto com antígeno Reo 198 de brucelose ovina

Fonte: Dados da pesquisa.

do ponto de corte apresentaram oscilação de densidade óptica de 0,412 a 0,782 (Gráfico 1). Verificouse que a média da densidade óptica das amostras não reagentes foi de 0,21 e das amostras reagentes foi de 0,597 , apresentando amostras com valores de densidade óptica superior ao ponto de corte em total 2,45\% da população investigada.

\section{Discussão}

$\mathrm{Xu}$ et al. (1997) ressaltam que a sensibilidade e a especificidade são características intrínsecas fundamentais para validar um teste diagnóstico. Assim, quanto maior a sensibilidade do teste, maior a capacidade de o teste positivo identificar o animal doente. Quanto maior a especificidade de um teste, maior a capacidade de o teste negativo excluir corretamente os animais que não possuem a doença (LOPEZ et al., 2000). A sensibilidade pode ser definida como a probabilidade de o teste ser positivo caso o animal esteja infectado, ao passo que a especificidade seria a probabilidade de o teste ser negativo no animal não infectado. No presente trabalho, constatou-se que o ELISA indireto com antígeno comercial possui uma capacidade maior de discriminar animais infectados de animais não infectados.
Tabela 1 - Estudo da sensibilidade, especificidade e ponto de corte de teste ELISA indireto com antígeno Reo 198 para brucelose ovina

\begin{tabular}{|c|c|c|}
\hline Sensibilidade (\%) & Especificidade (\%) & Ponto de corte \\
\hline 100 & 95,6 & 0,408 \\
\hline
\end{tabular}

Fonte: Dados da pesquisa.

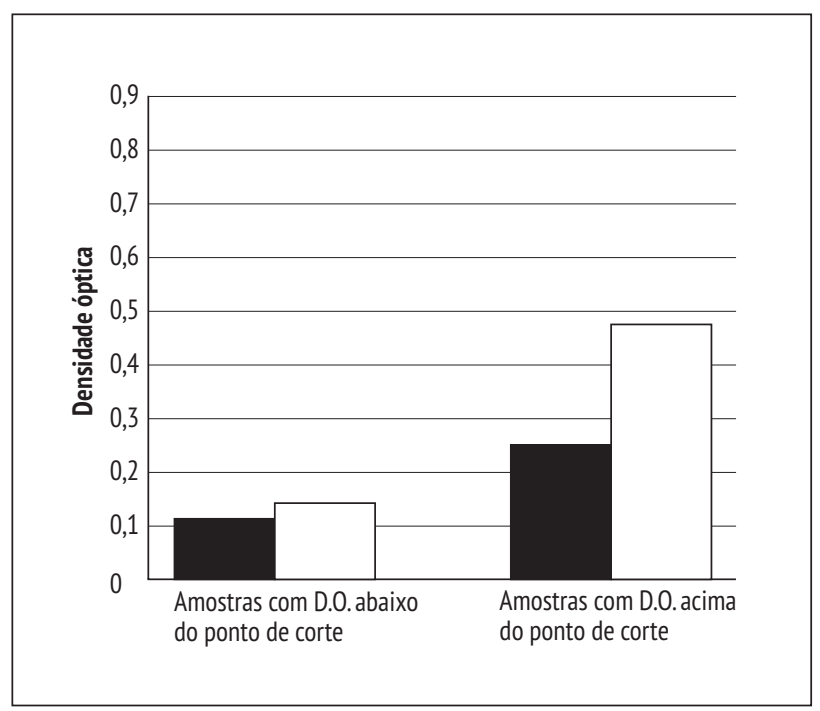

Gráfico 1 - Médias de D.O. referentes às 448 amostras testadas no ELISA indireto com antígeno Reo 198 de brucelose ovina

Fonte: Dados da pesquisa.

No entanto, Jorge (2007), utilizando antígenos de extrato preparado e padronizado no Laboratório de Doenças Infecciosas da União Metropolitana de Educação e Cultura (BA), como o obtido pela linhagem de Brucella canis, observou que existe uma diferença nos resultados obtidos dos animais infectados e não infectados, apresentando um desempenho menor com relação ao referido ELISA.

0 teste ELISA indireto, neste estudo, mostrou-se eficaz quando relacionado ao histórico clínico com os resultados obtidos, sendo proposto um teste de diagnóstico capaz de detectar um maior número de animais, facilitando o controle e a prevenção de rebanhos suspeitos da brucelose ovina. Contudo, a carência de técnicas de diagnóstico eficazes, bem como a falta de relato de sinais clínicos da doença no rebanho do Estado da Bahia, ressaltam a necessidade de se elaborar testes de diagnóstico com alta 
sensibilidade e especificidade, justificando a elaboração de um projeto desta natureza. Jorge (2007) utilizou o teste ELISA indireto para detectar anticorpos contra a Brucella ovis com um antígeno produzido a partir da Brucella canis, pois as proteínas de superfície dessas bactérias são similares. Os resultados foram satisfatórios, obtendo-se uma sensibilidade de $93,33 \%$ e especificidade de $88,88 \%$.

Em relação ao presente estudo, os resultados são diferentes dos de Jorge (2007), porém apresentam boa capacidade de discriminar animais infectados de animais não infectados. Aqui, o antígeno utilizado, apesar de diluído, é o mesmo preconizado pelo Ministério da Agricultura e testado por meio do ensaio imunoenzimático indireto, demonstrando eficácia estatística com sensibilidade de $100 \%$ e especificidade de $95,6 \%$.

Em uma pesquisa realizada para avaliar a sensibilidade e a especificidade do ELISA indireto, Cho e Niilo (1987) demonstraram que as diluições do antígeno utilizado no teste influenciaram os resultados obtidos. Os animais foram inoculados com a cepa de Brucella ovis e o soro desses animais foi submetido ao teste ELISA indireto com várias concentrações do antígeno, que oscilaram de 1:25 a 1:400. Na diluição de 1:25, o teste apresentou 99,4\% de especificidade, e nas diluições de 1:50 a 1:400,100\%. No entanto, Afzal et al. (1984), utilizando lipopolissacarídeo de Brucella ovis como antígeno na padronização de um teste ELISA indireto, obtiveram a diluição de 1:100 como melhor resultado entre as amostras positivas e negativas. Esse estudo respalda o presente trabalho com relação à melhor sensibilidade e especificidade encontradas na diluição de 1:200, demonstrando que a menor concentração do antígeno possibilita o reconhecimento de proteínas mais específicas, diminuindo a probabilidade de reações cruzadas.

As amostras testadas neste estudo foram utilizadas no IDGA e ELISA indireto. Os resultados associados ao histórico clínico observado no IDGA apresentaram uma similaridade com os resultados do ELISA indireto, capaz de detectar $100 \%$ dos animais com histórico clínico. Azevedo et al. (2004), utilizando o teste de imunodifusão em gel de ágar para analisar a ocorrência de anticorpos anti-Brucella ovis em ovinos procedentes de quatro municípios do Estado do Rio Grande do Norte, relataram que dos 115 ovinos submetidos ao teste, apenas 13 apresentaram reatividade, sendo que esses animais tinham sido examinados clinicamente e apresentavam histórico de epididimite.
Demonstra-se, consequentemente, que o exame clínico não é suficiente para diagnosticar a doença, uma vez que existem outros males que apresentam o mesmo sintoma. Desse modo, parece mais indicado que testes sorológicos de triagem sejam associados a testes confirmatórios, o que minimizaria a possibilidade de reações cruzadas e de falsos negativos e positivos.

A fim de demonstrar a eficiência entre os testes, Nozaki et al. (2004) compararam as técnicas de imunodifusão em gel de ágar e ELISA, e observaram discrepância entre os resultados. Os soros foram submetidos duas vezes ao teste de imunodifusão em gel de ágar, sendo encontrados, na primeira vez, $12 \%$ de animais reagentes. Já na segunda vez, os soros foram submetidos ao tratamento com 2-mercaptoetanol, apresentando apenas 1,1\% de animais reagentes. Em relação às amostras submetidas ao ELISA indireto, observaram que não houve animais reagentes que pudessem ser considerados positivos. Contrariamente ao estudo anterior dos mesmos autores, essa pesquisa apresentou resultados mais diferenciados com relação à imunodifusão e ao ELISA indireto, demonstrando que os testes podem ser utilizados com segurança e confiabilidade.

Essa teoria é relatada pela OIE (2000) ao preconizar que o ELISA apresenta maior sensibilidade que o teste de imunodifusão em gel de ágar ou a Fixação de Complemento, porém em função de alguns resultados ELISA negativos e imunodifusão positivos, a combinação do ELISA com o imunodifusão resultaria em melhor desempenho da sensibilidade.

Com a finalidade de verificar o desempenho do teste ELISA padronizado, foram submetidas 448 amostras de soro ovino provenientes de sete regiões do semiárido baiano. Verificou-se que 11 amostras apresentaram densidade óptica acima do valor de ponto de corte com um total de 2,45\% de ocorrência. Em levantamento realizado por Magalhães Neto e Gil-Turnes (1996), utilizando 76 rebanhos do Rio Grande do Sul, constatou-se a soroprevalência média em carneiros de rebanhos positivos de 13,4\% pelo teste imunodifusão em gel de ágar, com aumento da soroprevalência em animais mais velhos e sem predisposição racial definida. Resultados diferentes dos achados obtidos por Cardoso et al. (1989), em outra propriedade gaúcha, foram verificados com prevalência de 9,79\%.

Em um levantamento sorológico no Estado de São Paulo envolvendo 18 rebanhos em 15 
municípios, não foi encontrada evidência da infecção por Brucella ovis (MARINHO; MATHIAS, 1996), resultados contrários aos obtidos no presente estudo. Contudo, estudos de Azevedo et al. (2004) verificaram que a ocorrência de anticorpos anti-Brucella ovis leva a aceitar que a doença encontra-se presente, tornando-se um problema sanitário no rebanho ovino do Rio Grande do Norte. Silva et al. (2003), estudando a prevalência de brucelose ovina causada por Brucella ovis em rebanhos do Rio Grande do Norte, detectaram sorologia positiva em 13 municípios dos 14 estudados, verificando que a infecção por Brucella ovis está amplamente distribuída na região, afetando ovinos de ambos os sexos, adultos e jovens e de diferentes raças.

\section{Conclusões}

O antígeno comercial Reo 198 demonstrou desempenho satisfatório, distinguindo animais infectados e animais não infectados, quando empregado em ensaio piloto de um teste ELISA indireto para a detecção de anticorpos contra a brucelose ovina.

0 teste ELISA indireto com antígeno comercial Reo 198 diluído apresentou 100\% de sensibilidade e 95,6\% de especificidade, demonstrando uma maior capacidade de identificar animais reagentes, uma vez que, de um total de 448 amostras do Semiárido da Bahia submetidas ao IDGA, foram detectados $2,45 \%$ de amostras não reagentes a ele na população investigada.

\section{Referências}

AFZAL, M. et al. Characterization of Brucella ovis lipopolysaccharide and its use for diagnosis of ram epididymitis by enzyme-linked immunosorbent assay. Journal Clinical Microbiology, v. 20, n. 6, p. 1159-1164, 1984.

ARSENAULT, J. et al. Lack of evidence of Brucella ovis infection in rams in Quebec. Canadian Veterinary Journal, v. 45, p. $312-313,2004$.

AZEVEDO, S. S. et al. Ocorrência de anticorpos anti-Brucella ovis em ovinos procedentes de quatro municípios do Estado do Rio Grande do Norte; Brasil. Revista Agropecuária Técnica, v. 25, n. 2, p. 45-50, 2004.
CARDOSO, M. R. I. et al. Alterações da morfologia espermática em carneiros naturalmente infectados pela Brucella ovis. Arquivo da Faculdade de Veterinária, v. 17 , p. 39-48, 1989.

CHO, H. J.; NIILO, L. Diagnostic sensitivity and specificity of an enzyme-linked immunosorbent assay for the diagnosis of Brucella ovis infection in rams. Canadian Journal of Veterinary Research, v. 51, p. 99-103, 1987.

COLETO, Z. F. et al. Ocorrência de infecção por Brucella ovis em ovinos no estado de Pernambuco e sua participação em distúrbios reprodutivos nesta espécie. Revista Brasileira Saúde Produção Animal, v. 27, p. 551-553, 2003.

GREINER, M. et al. A modified ROC analysis for the selection of cut-off values and the definition of intermediate results of serodiagnostic tests. Journal of Immunology Methods, v. 185, p. 123-132, 1995.

JORGE, J. S. Produção e padronização de um antígeno para um ELISA indireto no diagnóstico da brucelose ovina. 2007. 45 f. Monografia (Graduação em Medicina Veterinária) - União Metropolitana de Educação e Cultura, Lauro de Freitas, BA, 2007.

LEITE, E. R. Ovinocaprinocultura no nordeste-organização e crescimento. 2000. Disponível em: <http://www. cnpc.embrapa.br/artigo14.htm>. Acesso em: 2 fev. 2010.

LOPEZ, J. F. et al. Corynebacterium pseudotuberculosis first case of human infection. American Journal of Clinical Pathology, v. 46, n. 5, p. $582-567,2000$.

MAGALHÃES NETO, A.; GIL TURNES, C. Brucelose ovina no Rio Grande do Sul. Pesquisa Veterinária Brasileira, v. 16, n. 213, p. 75-79, 1996.

MARINHO, M.; MATHIAS, L. A. Pesquisa de anticorpos contra Brucella ovis em ovinos do Estado de São Paulo. Pesquisa Veterinária Brasileira, v. 16, n. 213, p. 45-48, abr./set., 1996.

MYERS, D. M.; SINIUK, A. A. Preliminary report on the development of a difusion in gel method for the diagnosis of RAM epididimitis. Applied Microbiology, v. 19, p. 335$337,1970$.

NOZAKI, C. N. et al. Comparação das técnicas de imunodifusão em gel de Agar e ELISA no diagnóstico de brucelose ovina em cabanhas da região centro-oeste do Estado de São Paulo. Arquivos do Instituto Biológico, v. 71, n. 1, p. 1-5, 2004. 
OFFICE INTERNATIONAL DES ÉPIZOOTIES - OIE. Manual of Standards for Diagnostic Tests and Vaccines. 2000. Disponível em: <http://www.oie.int/international-standard-setting/terrestrial-manual/access-online/>. Acesso em: 10 out. 2010 .

PINHEIRO Jr., J. W. et al. Ocorrência de ovinos sororeatores para Brucella ovis no estado de Alagoas, Brasil. Veterinaria e Zootecnia, v. 16, n. 3, p. 500-508, 2009.

RIDLER, A. L. An overview of Brucella ovis infection in New Zealand. New Zealand Veterinary Journal, v. 50, n. 3, p. 96-98, 2002.

ROBLES, C. A. Epididimitis contagiosa de los carneros por Bruxelas ovis. Revista de Medicina Veterinária, v. 79, n. 1, p. 67-71, 1998.

SILVA, N. S. et al. Detecção de anticorpos anti-Brucella ovis em ovinos do estado da Bahia. Revista Brasileira Saúde Produção Animal, v. 10, n. 4, p. 852-859, 2009.
SILVA, J. B. A. et al. Prevalência de Brucelose ovina causada por Brucella ovis em rebanhos do Estado do Rio Grande do Norte; Brasil. Revista Ciência Animal, v. 13, n. 1, p. 51-54, 2003.

SOUZA, T. S. et al. Estudo sorológico da Maedi-Visna pelo método da imunodifusão em gel de ágar em rebanhos ovinos de Juazeiro, Bahia, Brasil. Revista Brasileira Saúde Produção Animal, v. 8, n. 4, p. 276-282, 2007.

$\mathrm{XU}, \mathrm{H}$. et al. The selection of ELISA cut-off points for testing antibody to Newcastle disease by two-graph receiver operating characteristic (TG-ROC) analysis. Journal Immunology Methods, v. 208, p. 61-64, 1997.

Recebido: $17 / 11 / 2010$

Received: $11 / 17 / 2010$

Aprovado: 10/08/2011

Approved: 08/10/2011 